\title{
The Aggregation of Bentonite Using Poly( $N$-isopropylacrylamide) as a Flocculant
}

\author{
Ayano Nakamura*, Kenji Murakami \\ Department of Materials Science, Faculty of Engineering Science, Akita University, Akita, Japan \\ Email: *nakamuraay@gipc.akita-u.ac.jp
}

How to cite this paper: Nakamura, A. and Murakami, K. (2018) The Aggregation of Bentonite Using Poly $(N$-isopropylacrylamide) as a Flocculant. Journal of Materials Science and Chemical Engineering, 6, 94-108. https://doi.org/10.4236/msce.2018.64011

Received: March 15, 2018

Accepted: April 14, 2018

Published: April 17, 2018

Copyright $\odot 2018$ by authors and Scientific Research Publishing Inc. This work is licensed under the Creative Commons Attribution-NonCommercial International License (CC BY-NC 4.0). http://creativecommons.org/licenses/by-nc/4.0/ (c) (i) (8) Open Access

\begin{abstract}
Sedimentation tests of bentonite suspension were carried out by adding various concentrations of poly ( $N$-isopropylacrylamide) (PNIPAM) with different molecular weights as flocculant below and above lower critical solution temperature (LCST). Also, the effect of PNIPAM on aggregation of bentonite was investigated by sedimentation rate, turbidity of supernatant. Additionally, XRD patterns and SEM photographs were measured in order to consider aggregation mechanism of PNIPAM. The sedimentation rate and turbidity for the PNIPAM with large molecular weight or PNIPAM solution of high concentration above LCST were faster and clearer than those with small molecular weight or low concentration. From XRD patterns, the peak of bentonite sediment with PNIPAM shifted to the low-angle side, suggesting that a part of PNIPAM chain entered between bentonite layers. Furthermore, it was confirmed by SEM photographs that PNIPAM covered bentonite surface after sedimentation test. It was indicated that PNIPAM adsorbs on the bentonite surface and aggregates each bentonite particle above LCST. From these results, PNIPAM works as a flocculant and the PNIPAM with large molecular weight has a good ability.
\end{abstract}

\section{Keywords}

Bentonite, Sedimentation, Flocculant, Temperature-Responsive Polymer, Molecular Weight

\section{Introduction}

Bentonite is a layered clay mineral, whose main component is montmorillonite composed of 2:1-layer structure of two tetrahedral silica sheets sandwiching one octahedral alumina sheet [1] [2]. In the tetrahedral silica sheet and octahedral alumina sheet of montmorillonite, some $\mathrm{Si}^{4+}$ and $\mathrm{Al}^{3+}$ are exchanged with $\mathrm{Al}^{3+}$ 
and $\mathrm{Mg}^{2+}$, respectively [3] [4] [5]. As a result, surface of silica and alumina sheets has negative charges [6] [7]. These negative charges are balanced by cations, such as $\mathrm{Ca}^{2+}$ or $\mathrm{Na}^{+}$, intercalated between the structural platelets/sheets. When the bentonite is immersed in water, the bentonite is well dispersed in water [8] [9] [10] [11]. The bentonite suspension is used as lubricant at drilling construction site [12] [13] [14], where a large amount of used-bentonite suspension is generated [15] [16]. However, the separation of bentonite from water is very hard due to the strong affinity between bentonite and water. Hence, the used-bentonite suspension must be loaded onto many trucks and carried to water treatment facilities. In other words, it takes enormous cost to carry and treat these suspensions.

To solve this problem, coagulating sedimentation method is generally used to separate bentonite and treated water by adding flocculant [17]. As general flocculants, aluminium- or iron-based inorganic flocculant and polymeric flocculant such as polyacrylamide are used [18] [19]. However, it is necessary to construct an additional dewatering process because these flocculants aggregate soil particles with a large amount of water [20] [21].

Recently, temperature-responsive polymer is expected as a new flocculant. The temperature-responsive polymers, such as $\operatorname{poly}(N$-vinyl- $\varepsilon$-caprolactam) [22] [23], poly(2-ethoxyethylvinylether) (EOVE) [24], poly( $N$-isopropylacrylamide) (PNIPAM), change their volumes at a certain temperature. In this study, PNIPAM, which has been well known in all the temperature-responsive polymers, was used. PNIPAM has a lower critical solution temperature (LCST) at $32^{\circ} \mathrm{C}$. Below its LCST, PNIPAM is soluble in aqueous solution. On the other hand, above its LCST, PNIPAM turns hydrophobic due to strong intermolecular hydrogen bonding. This reversible solubility of PNIPAM is attributed to a coil-globule conformational transition of polymer chains [25] [26] [27]. Hence, PNIPAM is applied to not only a drug delivery system [28] [29] and an actuator [30], but also flocculant. In the case of applying PNIPAM to flocculant, it is expected that PNIPAM adsorbs on the surface of soil particles below $32^{\circ} \mathrm{C}$. Above $32^{\circ} \mathrm{C}$, PNIPAM aggregates with soil particles and dewaters because PNIPAM shrinks with dehydrating. Some reports about PNIPAM flocculant, such as aggregation behavior of the mixture of silica and alumina with PNIPAM [21] [31] and aggregation of quartz with copolymer of PNIPAM and other polymer [32], have been already published. Moreover, there are reports that the larger molecular weight of thermo-responsive polymer is, the bigger flocs become [31] [32]. However, the reports of bentonite aggregation with PNIPAM as flocculant cannot be found except for our studies. Also, it is not clear how PNIPAM affects the aggregation of bentonite.

In this study, aggregating performance of PNIPAM for bentonite was observed by sedimentation test. Furthermore, the effect of molecular weight of PNIPAM on aggregation behavior in the temperature change was investigated by observation of the change in sedimentation rate and volume and by measur- 
ing turbidity of supernatant solution after sedimentation test. In addition, a role of PNIPAM on bentonite aggregation was discussed by evaluating shift of diffraction angle of bentonite sediment, from X-ray diffraction (XRD) patterns, and the change in morphology of bentonite surface, from scanning electron microscopy (SEM), with change in molecular weight and concentration of PNIPAM.

\section{Experimental}

\subsection{Materials}

Natural bentonite (Raw bent) from Gunma prefecture in Japan was used as a sample in this study. $N$-isopropylacrylamide (NIPAM) and ammonium peroxodisulfate (APS) were obtained from Wako Ltd. (Japan). $N, N, N^{p}, N^{p}$-tetramethylethylenediamine (TMEDA) was obtained from Nacalai tesque Inc. (Japan). APS aqueous solution of $5,10,30 \mathrm{mg} / \mathrm{mL}$ and TMEDA aqueous solution of $0.02 \mathrm{mg} / \mathrm{mL}$ were prepared.

\subsection{Characterization of Bentonite}

Chemical composition of Raw bent was measured by X-ray fluorescence spectroscopy (XRF, Shimadzu, XRF-1700 (4 kW)). The Raw bent dried at $100^{\circ} \mathrm{C}$ for $1 \mathrm{~h}$ was pressed at $30 \mathrm{t}$ and used for XRF measurement. The particle size distribution (PSD) of Raw bent suspended in ethanol was measured by laser diffraction scattering method (Microtrac BEL, MT3300EX II). Raw bent was analyzed by XRD (Rigaku, Ultimate IV) with $\mathrm{Cu}-\mathrm{K} \alpha$ radiation $(\lambda=0.154 \mathrm{~nm})$ operating at $40 \mathrm{kV}$ and $40 \mathrm{~mA}$ to investigate an interlayer spacing $\left(d_{001}\right)$. The sample was scanned from $2^{\circ}$ to $25^{\circ}$ at intervals of $0.02^{\circ}$ at a rate of $2^{\circ} / \mathrm{min}$. The $d_{001}$ was calculated by Bragg's Law as follows:

$$
n \lambda=2 d_{001} \sin \theta
$$

where $n$ is a positive integer $(n=1)$ and $\theta$ is a glancing angle. The zeta potential of Raw bent in the suspension prepared by adding Raw bent $(0.2 \mathrm{~g})$ into $50 \mathrm{~mL}$ of water, was measured by ELSZ-1000ZS (Ohtsuka).

\subsection{Synthesis of PNIPAM}

The PNIPAM was synthesized by the radical polymerization method [33] [34] [35]. NIPAM (2 g) and distilled water $(100 \mathrm{~mL})$ were put into a two-necked separable flask and the solution was stirred for 30 min with $\mathrm{N}_{2}$ bubbling for removing oxygen. After $30 \mathrm{~min}, 10 \mathrm{~mL}$ of APS aqueous solution $(5,10,30$ $\mathrm{mg} / \mathrm{mL}$ ), which was sonicated for 10 min owing to remove oxygen before use, was added as an initiator and the solution was stirred for $10 \mathrm{~min}$. After that, 10 $\mathrm{mL}$ of TMEDA aqueous solution sonicated for $10 \mathrm{~min}$ was added as an accelerator and the solution was stirred for $4 \mathrm{~h}$. After the reaction for $4 \mathrm{~h}$, this solution was put into dialysis cellulose membrane (pore size is $50 \AA$ ) and dialysis was performed four times for $12 \mathrm{~h}$. Finally, the dialyzed solution was dried at $60^{\circ} \mathrm{C}$ 
for 2 days.

Fourier transform infrared (FT-IR) spectra of PNIPAM were measured by transmission method (Shimadzu, IRAffinity-1). The measurement conditions were a wavenumber range of $4000-600 \mathrm{~cm}^{-1}$, resolution of $2 \mathrm{~cm}^{-1}$, and scan number of 32. Sample pellets were made by dropping $20 \mu \mathrm{L}$ of PNIPAM aqueous solution $(10 \mathrm{~g} / \mathrm{L})$ to $99.5 \mathrm{mg}$ of $\mathrm{KBr}$. The molecular weight of PNIPAM was estimated by the viscosity of PNIPAM aqueous solution. The PNIPAM aqueous solution of $0.05,0.2,0.51 .0 \mathrm{~g} / \mathrm{dL}$ was prepared by dissolving dried PNIPAM in water. These solutions of $10 \mathrm{~mL}$ were put into the Ostwald viscometer and the viscosity was measured. The molecular weight $\left(M_{n}\right)$ of PNIPAM was calculated by using Mark-Houwink-Sakurada equation shown in the following equation;

$$
\eta=K \cdot M_{n}^{\alpha}
$$

where $\eta$ is the intrinsic viscosity of PNIPAM aqueous solution, $K$ and $\alpha$ are specific constant of PNIPAM at 0.0145 and 0.5 , respectively [36].

\subsection{Sedimentation Test}

The sedimentation test of bentonite was performed by using a graduated cylinder $(50 \mathrm{~mL})$. Raw bent $(0.25 \mathrm{~g})$ and distilled water $(40 \mathrm{~mL})$ were added in the graduated cylinder and the bentonite particles were shaken vigorously until completely dispersed in distilled water. The graduated cylinder was filled with distilled water to the marked line after $100-800$ ppm of PNIPAM was added into bentonite suspension. This suspension including PNIPAM was shaken by turning upside down 15 times repeatedly by hand, and the sedimentation test was carried out as follows: The bentonite suspension was heated up to $50^{\circ} \mathrm{C}$ and kept at the temperature for $15 \mathrm{~min}$ in thermostatic chamber. After that, it was re-shaken in 15 times of the same operation as above and the change of sedimentation volume was observed at $50^{\circ} \mathrm{C}$ for $30 \mathrm{~min}$. As a comparative experiment, the same experiment was carried out at $25^{\circ} \mathrm{C}$ in order to observe the difference in sedimentation performance of PNIPAM due to temperature difference. The sedimentation test was repeated at least three times and the sediment volume was expressed as the average value. After $30 \mathrm{~min}, 10 \mathrm{~mL}$ of the supernatant solution was collected at the height of $20 \mathrm{~mL}$ from the top of graduated cylinder in order to measure turbidity in the supernatant solution. The turbidity was measured by turbidity meter (Thermo Scientific, TN-100) at least three times. The turbidity in this turbidity meter is given by nephelometric turbidity unit (NTU) and can be measured up to 2000 NTU. The measurement of turbidity was carried out after $10 \mathrm{~min}$ of cooling because the supernatant containing PNIPAM was slightly cloudy at $50^{\circ} \mathrm{C}$. Then, the calibration curve was made by measuring turbidity of bentonite suspension adjusted to a predetermined concentration $(100,500,1000,2000 \mathrm{mg}$-Raw bent/L). The ratio of floating bentonite was calculated from bentonite weight in supernatant based on the calibration curve and expressed as the average value. The suspension after sedimentation test was subsequently filtered with filter paper of $1 \mu \mathrm{m}$ pore size. The residues 
were dried at $60^{\circ} \mathrm{C}$ for $12 \mathrm{~h}$. After drying, these dried residues were analyzed by XRD under the same conditions as the case of Raw bent. The surface morphologies of the dried residues were also observed using SEM (Hitachi, S-4500) after crushing the residues.

\section{Results and Discussion}

\subsection{Characterization of Raw Bentonite}

The composition of Raw bent is as follows, in terms of wt\% of the respective oxides, $\mathrm{SiO}_{2}$ (73.43), $\mathrm{Al}_{2} \mathrm{O}_{3}$ (13.91), $\mathrm{Na}_{2} \mathrm{O}$ (3.45), $\mathrm{MgO}$ (2.81), $\mathrm{CaO}$ (2.54), $\mathrm{Fe}_{2} \mathrm{O}_{3}$ (2.43), $\mathrm{K}_{2} \mathrm{O}$ (1.12), $\mathrm{TiO}_{2}(0.22)$, and $\mathrm{MnO}$ (0.05). The particle size analysis of Raw bent is shown in Figure 1. The particle size of Raw bent ranged from 1 to $60 \mu \mathrm{m}$. Basal spacing of (001) plane for Raw bent $\left(d_{001}\right)$ was $1.27 \mathrm{~nm}$ [12] [37]. Furthermore, the zeta potential of Raw bent was $-37 \mathrm{mV}$.

\subsection{Characterization of PNIPAM}

PNIPAM molecular weight for adding initiator of 5,10 and $30 \mathrm{mg} / \mathrm{mL}$ was $M n=$ $700,000,270,000$ and 140,000, respectively. These PNIPAM are referred to PN700, PN270 and PN140.

Figure 2 shows the FT-IR spectra of PNIPAM between 3500 and $1000 \mathrm{~cm}^{-1}$. Six remarkable bands of PNIPAM appeared: C-H stretching vibrations at 2970, 2938, and $2875 \mathrm{~cm}^{-1}$, a $\mathrm{C}=\mathrm{O}$ stretching vibration of an amide group at 1640 $\mathrm{cm}^{-1}$, an N-H bending vibration of an amide group at $1540 \mathrm{~cm}^{-1}$, and a C-H bending vibration at $1425 \mathrm{~cm}^{-1}$ [38] [39] [40]. These results indicated that PNIPAM was synthesized. The change of spectrum due to the difference of PNIPAM molecular weight was not observed.

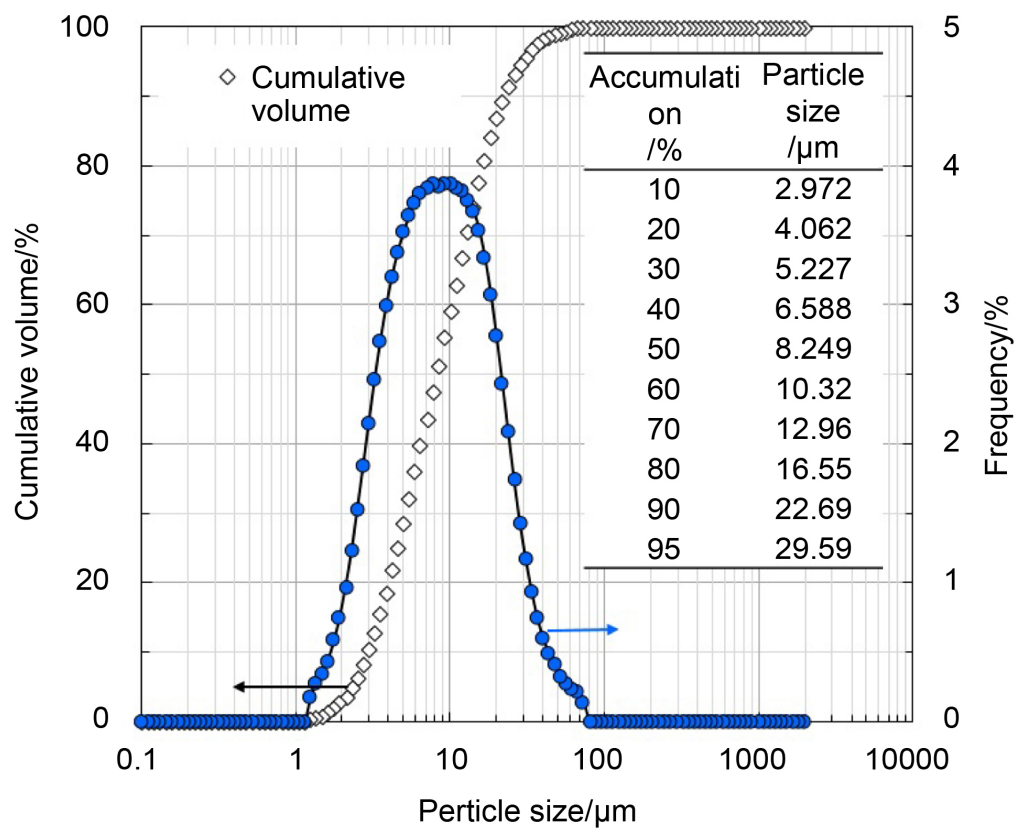

Figure 1. Particle size distribution of Raw bent. 


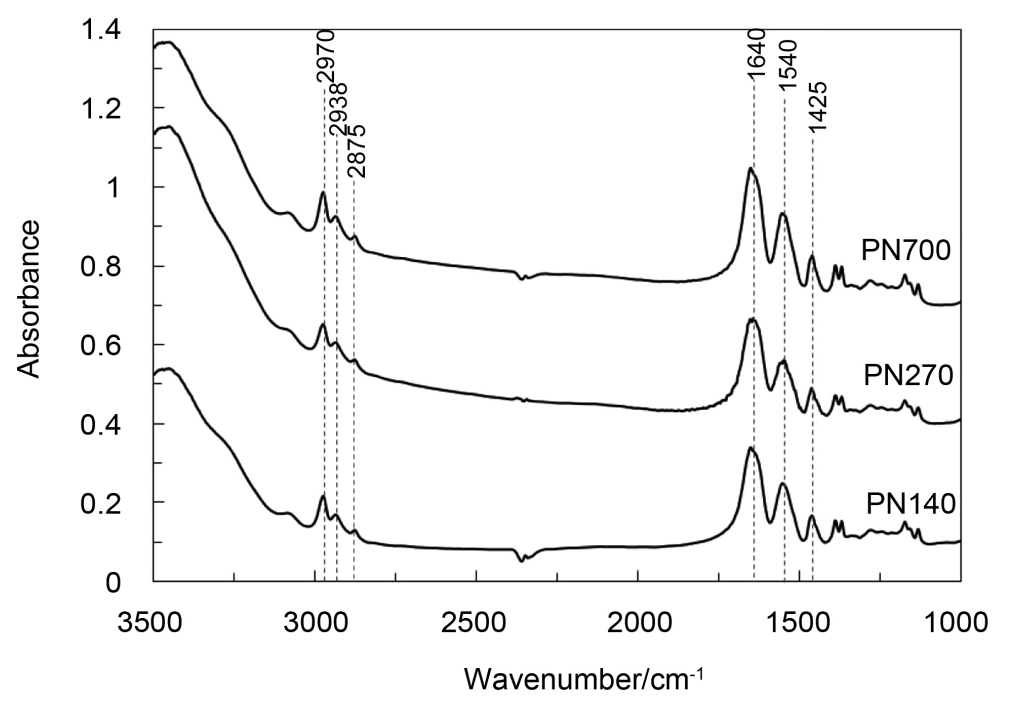

Figure 2. FT-IR spectra of three type of PNIPAM.

\subsection{Sedimentation Volume and Turbidity}

Figure 3 shows illustration of sedimentation test with 600 ppm of PN700 and PN140 at $25^{\circ} \mathrm{C}$ and $50^{\circ} \mathrm{C}$. Immediately after shaking $(0 \mathrm{~min})$, the boundary between sediment and supernatant solution could not be distinguished in all cases, as shown in Figures 3(a)-(d). After $30 \mathrm{~min}$, in the case of $25^{\circ} \mathrm{C}$ (Figure 3(e) and Figure 3(f)), a part of bentonite particles accumulated, but the other remained dispersed in the suspension [41]. On the other hand, at $50^{\circ} \mathrm{C}$, sediment due to floc formation was observed, and as a result, the boundary between sediment and supernatant appeared, as shown in Figure 3(g) and Figure 3(h). From this result, it can be said that PNIPAM works as a flocculant in response to temperature change.

Figures 4(a)-(c) show the change in sedimentation volume with time for 100 $800 \mathrm{ppm}$ of three types of PNIPAM at $50^{\circ} \mathrm{C}$. Regardless of the molecular weight of PNIPAM, there was a tendency that the sedimentation rate increased and the sedimentation volume decreased with increasing the addition amount of PNIPAM. However, the boundary between sediment and supernatant solution could not be observed in the case of $100-400$ ppm of PN140 and $100-200$ ppm of PN270. Also, as the molecular weight of PNIPAM increased, sediment due to floc formation was observed even with a smaller amount of PNIPAM and sedimentation rate increased for $5 \mathrm{~min}$ after start of the measurement. Moreover, it was found that the difference in sedimentation rate and volume was hardly observed in conditions of 100 - 500 ppm of PN700, 400 - 600 ppm of PN270, 500 $800 \mathrm{ppm}$ of PN140. The boundary between sediment and supernatant solution observed in this study indicates the terminal sedimentation rate of minimum bentonite particles. Therefore, because it is considered that floc size was difficult to grow for PNIPAM of small molecular weight or PNIPAM solution of low concentration, the sedimentation rate did not change. In contrast, the final sedimentation volume in condition of $600-800$ ppm of PN700 and 800 ppm of 


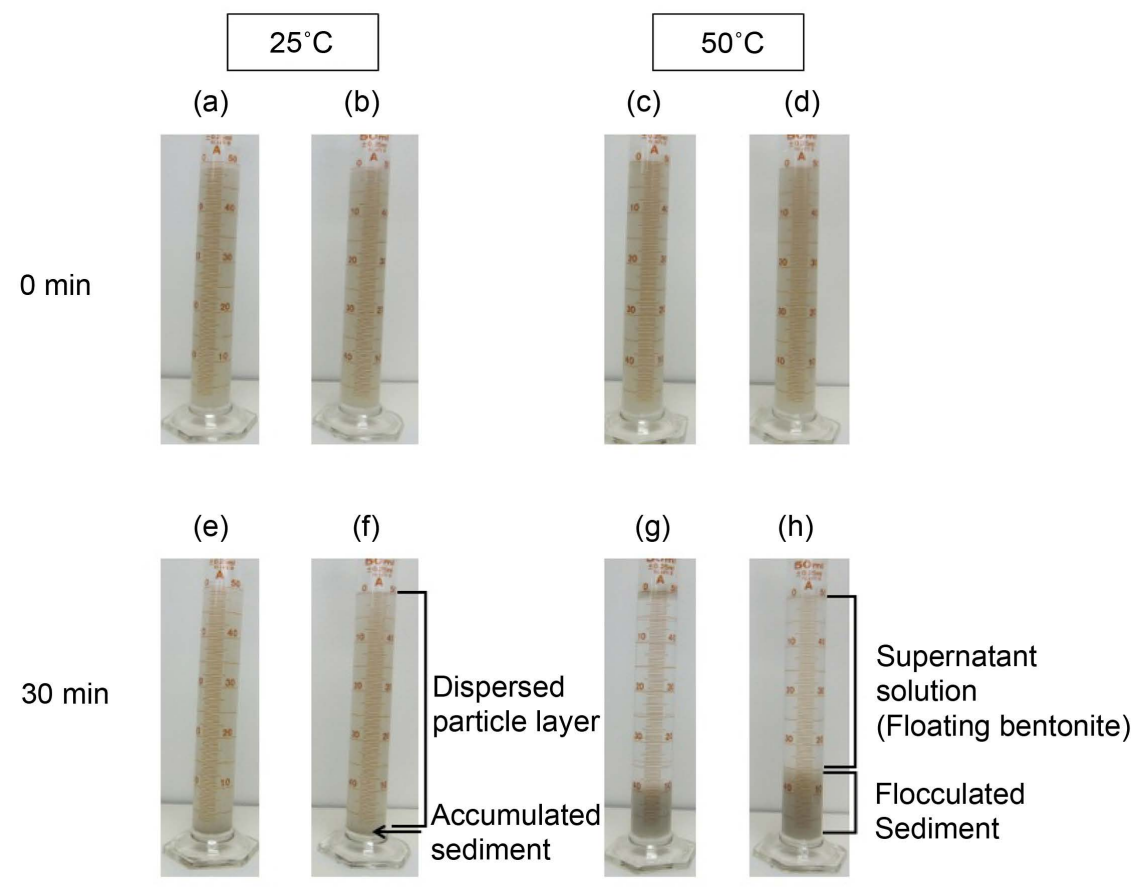

Figure 3. Illustration of sedimentation test with $600 \mathrm{ppm}$ of (a,e) PN700 and (b,f) PN140 at $25^{\circ} \mathrm{C},(\mathrm{c}, \mathrm{g})$ PN700 and $(\mathrm{d}, \mathrm{h}) \mathrm{PN} 140$ at $50^{\circ} \mathrm{C}$.

PN270 was smaller than that in the other conditions (Table 1), suggesting that the floc size or floc weight increased.

Additionally, ratios of floating bentonite in the supernatant solution for the suspensions including PNIPAM with various molecular weights are shown in Figure 5 . The ratio of floating bentonite was calculated by using turbidity shown in Table 1 . The turbidity without polymer could not be measured because the turbidity exceeded the detection limits (2000 NTU). The ratio of floating bentonite for $100 \mathrm{ppm}$ of PN700 was about $7 \mathrm{wt} \%$, while that for $400 \mathrm{ppm}$ or more of PN700 was less than $1 \mathrm{wt} \%$. On the other hand, the ratio of floating bentonite for $200 \mathrm{ppm}$ of PN140 was about $24 \mathrm{wt} \%$, indicating that one-fourth bentonite was floating in supernatant solution. Also, the ratio of floating bentonite for $800 \mathrm{ppm}$ of PN140 decreased to $3 \mathrm{wt} \%$. It was found that increasing the molecular weight and the concentration of PNIPAM in solution resulted in not only the increase in sedimentation rate (Figure 4), but also the decrease in the ratio of floating bentonite.

From these results, by using PNIPAM with large molecular weight or PNIPAM solution of high concentration, PNIPAM involves more floating bentonite in supernatant solution and make large and heavy floc. For this reason, sedimentation rate increased and sedimentation volume decreased by gravity of floc.

\subsection{Aggregation State with PNIPAM}

XRD patterns of bentonite residue after performing sedimentation test with 


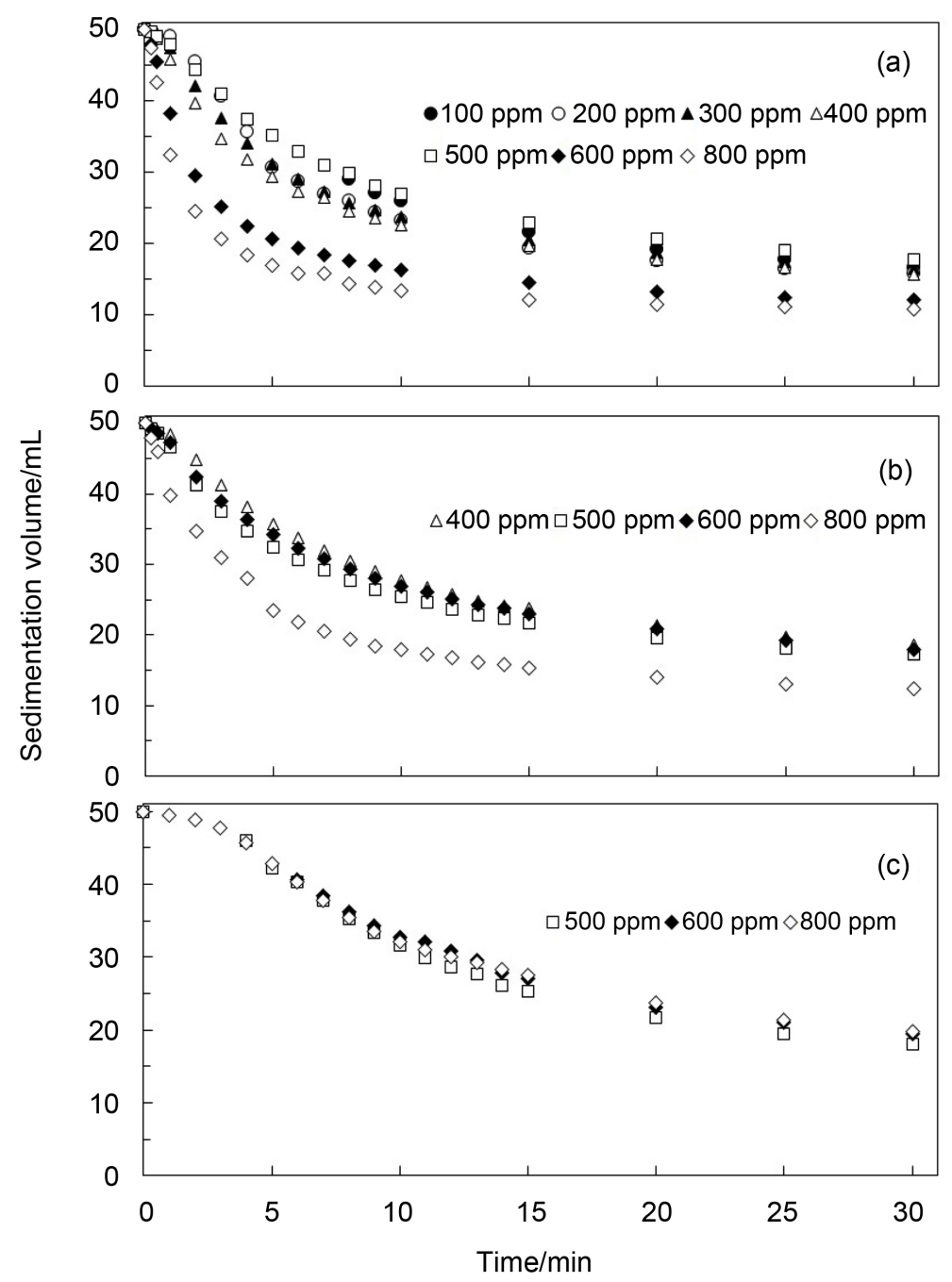

Figure 4. The change in sedimentation volume at $50^{\circ} \mathrm{C}$ for $100-800 \mathrm{ppm}$ of (a) PN700, (b) PN270 and (c) PN140.

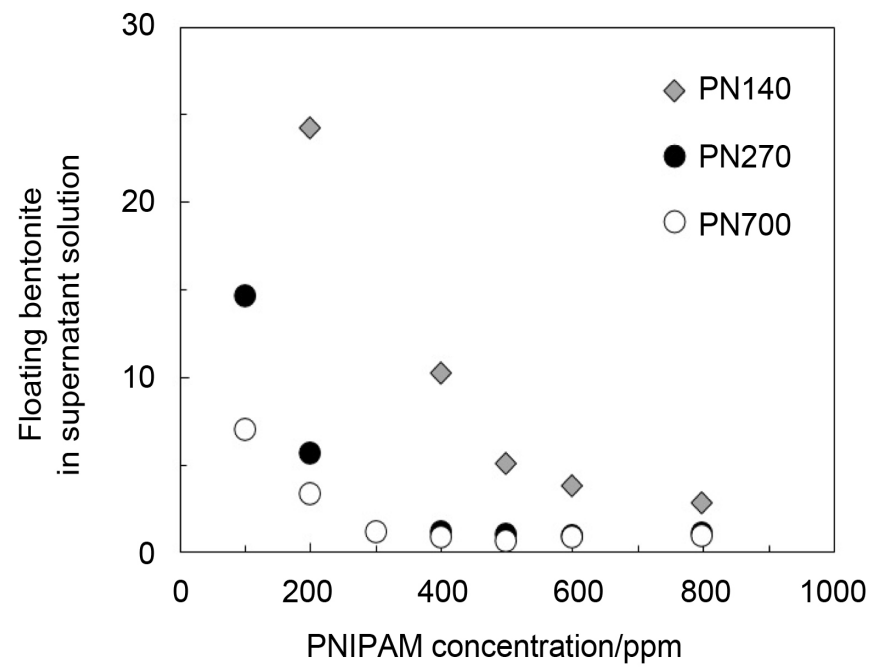

Figure 5. Ratio of floating bentonite in supernatant solution for the suspensions containing PNIPAM with various molecular weights. 
Table 1. Average of the final sedimentation volume after $30 \mathrm{~min}$ and average of turbidity in supernatant.

\begin{tabular}{ccccccc}
\hline \multirow{2}{*}{$\begin{array}{c}\text { PNIPAM } \\
\text { concentration/ppm }\end{array}$} & \multicolumn{2}{c}{ PN700 } & \multicolumn{2}{c}{ PN270 } & \multicolumn{2}{c}{ PN140 } \\
\cline { 2 - 7 } & $\begin{array}{c}\text { Volume/ } \\
\mathrm{mL}\end{array}$ & $\begin{array}{c}\text { Turbidity/ } \\
\text { NTU }\end{array}$ & $\begin{array}{c}\text { Volume/ } \\
\mathrm{mL}\end{array}$ & $\begin{array}{c}\text { Turbidity/ } \\
\text { NTU }\end{array}$ & $\begin{array}{c}\text { Volume/ } \\
\mathrm{mL}\end{array}$ & $\begin{array}{c}\text { Turbidity/ } \\
\text { NTU }\end{array}$ \\
\hline 100 & 16.6 & 230 & ${ }^{\star} 1$ & 464 & ${ }^{*} 1$ & 1668 \\
200 & 15.8 & 98.7 & ${ }^{\star} 1$ & 173 & ${ }^{\star} 1$ & 670 \\
300 & 16.5 & 24.5 & & & & \\
400 & 15.7 & 13.0 & 18.6 & 27.3 & ${ }^{\star} 1$ & 312 \\
500 & 17.8 & 6.9 & 17.3 & 21.1 & 18.1 & 170 \\
600 & 12.1 & 9.1 & 17.9 & 17.8 & 19.5 & 129 \\
800 & 10.8 & 10.0 & 12.4 & 16.7 & 19.8 & 94.4 \\
\hline
\end{tabular}

*1 The final sedimentation volume was unmeasurable.

PNIPAM at $50^{\circ} \mathrm{C}$ were shown in Figure 6 and Figure 7. The diffraction peak of (001) plane of bentonite shifted from $2 \theta=6.9^{\circ}\left(d_{001}=1.27 \mathrm{~nm}\right)$ for Raw bent to $2 \theta=4.4^{\circ}-5.5^{\circ}\left(d_{001}=1.6-2.0 \mathrm{~nm}\right)$ for the bentonite residues at $50^{\circ} \mathrm{C}$ regardless of molecular weight. And peak intensity slightly increased with increasing PNIPAM concentration from 100 to $400 \mathrm{ppm}$. These peak shifts and increases in intensity suggest that a part of polymer chain entered between bentonite layers [42] [43].

Above results indicate that it is easy to adsorb PNIPAM on the surface of bentonite by hydrogen bond below LCST. This hydrogen bond would form between hydrogen of N-H bond in the PNIPAM molecule and oxygen of Si-O bond in the bentonite surface or between oxygen of $\mathrm{C}=\mathrm{O}$ bond in the PNIPAM molecule and hydrogen of O-H bond in the bentonite surface. [6] [43] [44].

The SEM photographs of the surface morphologies of bentonite residue at $50^{\circ} \mathrm{C}$ are shown in Figure 8. When PNIPAM was present, unlike Raw bent, it was confirmed that the PNIPAM covered the surface of bentonite residue. Moreover, it was also found that the amount of PNIPAM on the surface of bentonite residue increased with increasing the molecular weight and concentration of PNIPAM.

From results of XRD patterns and SEM photographs, below LCST, PNIPAM adsorbed bentonite particles by hydrogen bond, while bentonite particles covered with PNIPAM were aggregated by hydrophobic interaction above LCST. Therefore, when PNIPAM with large molecular weight is used, it is expected that the coverage of PNIPAM will be high, so that floc size will increase (that is, the floc density will become high). Furthermore, PNIPAM with large molecular weight may be adsorbed to more bentonite particles, resulting in the high-density floc. As a result, the sedimentation rate is considered to be faster. On the other hand, PNIPAM with small molecular weight such as PN140 could not make large flocs because PNIPAM with small molecular weight does not have sufficient length to attract between bentonite particles. However, when the 
(a) PN700

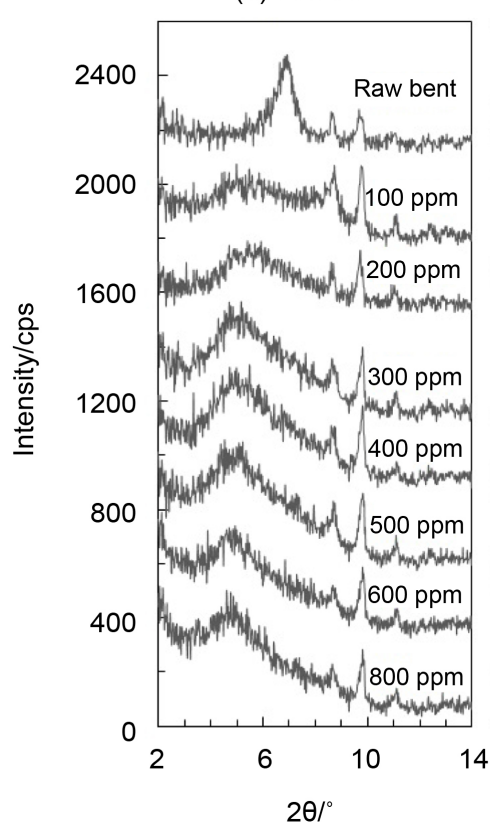

(b) PN270

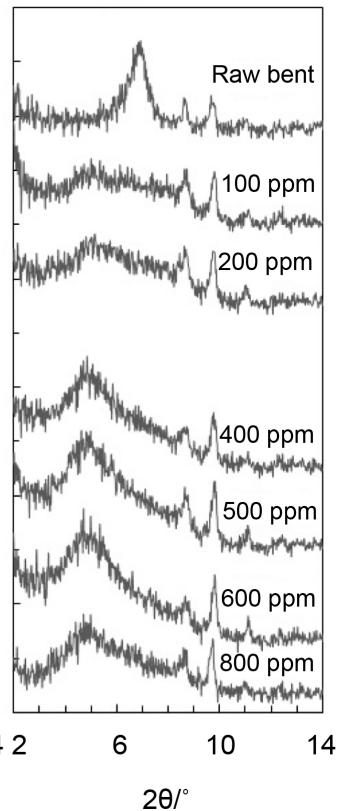

(c) PN140

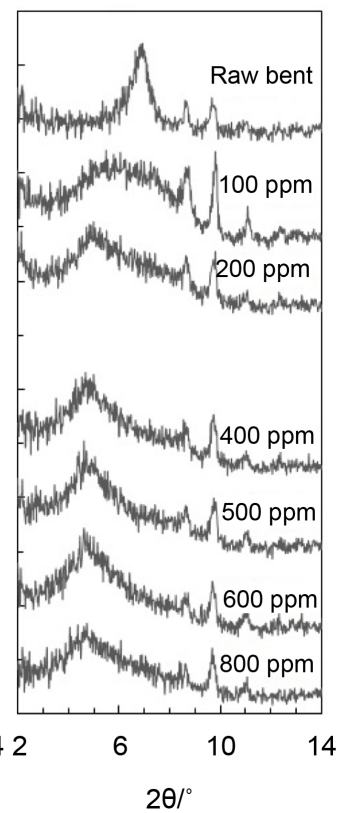

Figure 6. XRD patterns of Raw bent, and bentonite residues with $100-800$ ppm of (a) PN700, (b) PN270 and (c) PN140 at $50^{\circ} \mathrm{C}$.

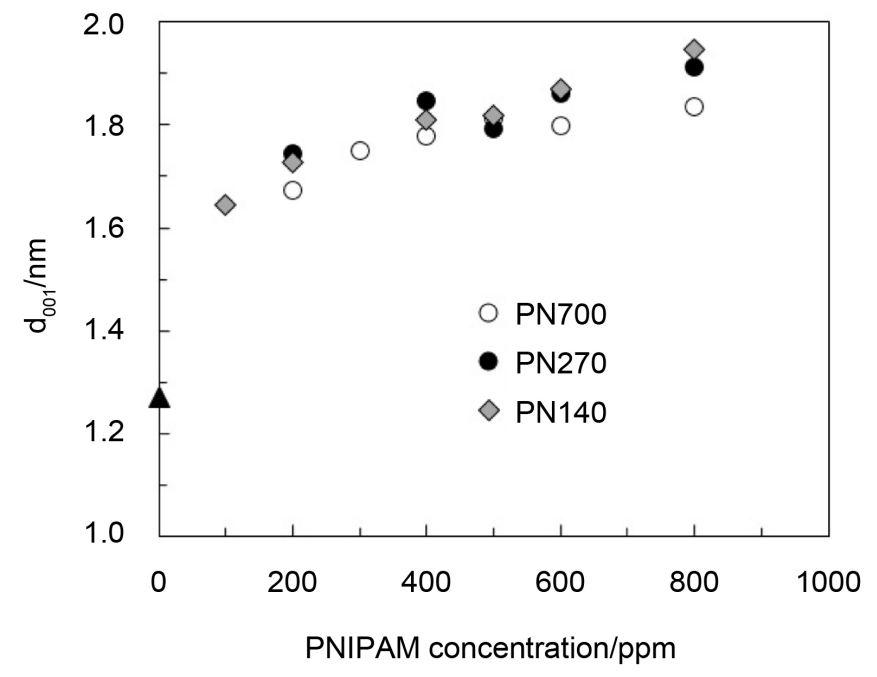

Figure 7. The change of $d_{001}$ for RT bentonite and different concentration of three PNIPAM molecular weights.

concentration of PNIPAM in solution increase, the turbidity in the supernatant solution became clear. It was considered that each PNIPAM chain with small molecular weight connected by hydrogen bond and got entangled [6] [45]. Thus, aggregates formed by a large number of PNIPAM with small molecular weight behaved as PNIPAM with large molecular weight and these PNIPAM attracted bentonite layers.

Consequently, PNIPAM is beneficial as flocculant due to high-density floc formation above LCST. In addition, PNIPAM with large molecular weight, such 
(a) Raw bent

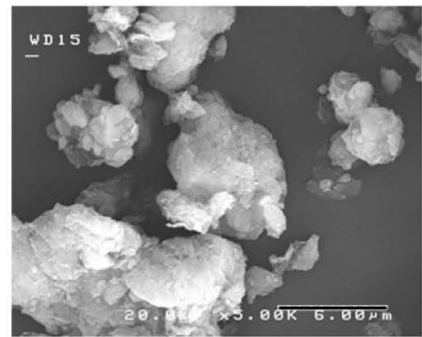

(e) Raw bent

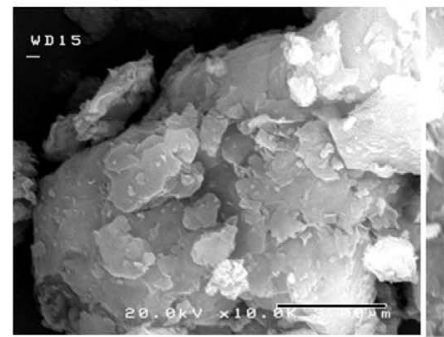

(b) PN140 800 ppm

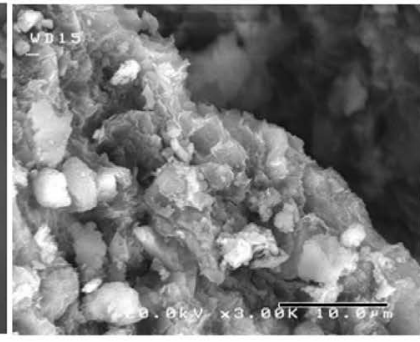

(f) PN140 800 ppm

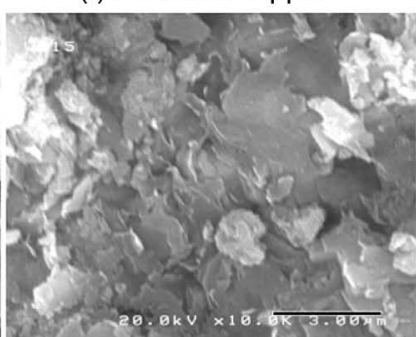

(c) PN700 100 ppm

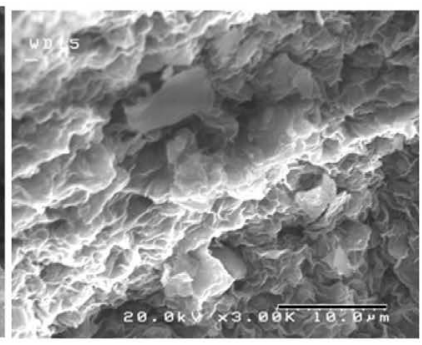

(g) PN700 100 ppm

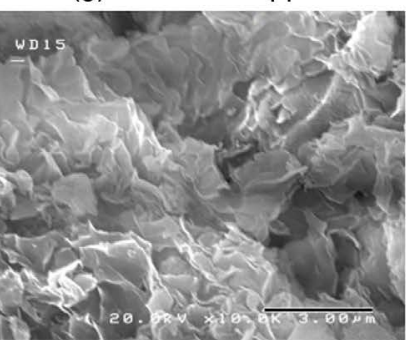

(d) PN700 800 ppm

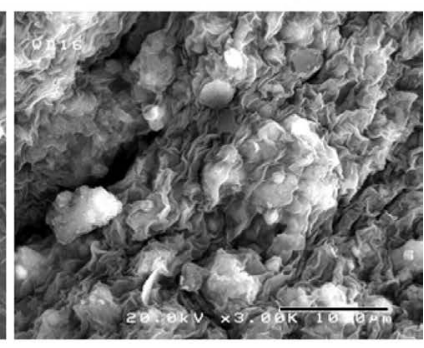

(h) PN700 800 ppm

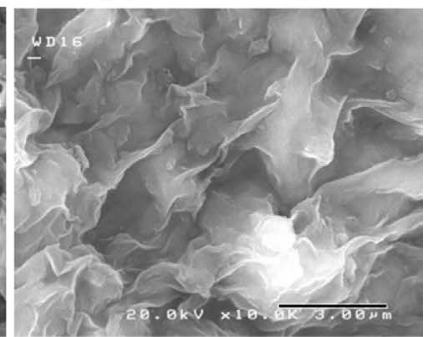

Figure 8. SEM photographs of (a,e) Raw bent, (b,f) 800 ppm of PN140, (c,g) 100 ppm of PN700 and (d,h) 800 ppm PN700. The scale bar in the photographs (a), (b)-(d) and (e)-(h) are 6, 10 and $3 \mu \mathrm{m}$, respectively.

as PN700, is the most effective because it can be easy to aggregate and precipitate bentonite particles and purify the supernatant solution.

\section{Conclusions}

The effect of PNIPAM on aggregation of bentonite was investigated and aggregation mechanism of bentonite with PNIPAM was considered.

- The sedimentation rate became faster and the sedimentation volume decreased when PNIPAM of large molecular weight such as PN700 and large number of PNIPAM were used.

- The supernatant solution with more than $400 \mathrm{ppm}$ of PN700 was the clearest (the ratio of floating bentonite was less than 1\%) among all experiments, while the ratio of floating bentonite for $800 \mathrm{ppm}$ of PN140 decreased to 3 wt\%.

- The interlayer spacing of (001) plane increased from $1.27 \mathrm{~nm}$ for Raw bent to $1.6-2.0 \mathrm{~nm}$ for the bentonite residues above LCST.

- SEM photographs revealed that PNIPAM covered the surface of bentonite residue. Moreover, the amount of PNIPAM on the surface increased with increasing the molecular weight and concentration of PNIPAM solution.

From these results, it is concluded that PNIPAM is beneficial as flocculant: PNIPAM is easy to adsorb bentonite surface by hydrogen bond below LCST and these bentonite particles are aggregated above LCST. In order to achieve high sedimentation rate using PNIPAM with small molecular weight, a large number of PNIPAM must be used. Therefore, because PNIPAM with large molecular weight make a high-density floc, the bentonite floc is able to precipitate faster and the supernatant solution is purified. 


\section{Acknowledgements}

This work was supported financially by Sanwa Tekki Corporation. Parts of measurement were supported in Akita Industrial Technology Center.

\section{References}

[1] Suzuki, S., Prayongphan, S., Ichikawa, Y. and Chae, B.-G. (2005) In situ Observations of the Swelling of Bentonite Aggregates in $\mathrm{NaCl}$ Solution. Applied Clay Science, 29, 89-98. https://doi.org/10.1016/j.clay.2004.11.001

[2] Clem, A.G. and Doehler, R.W. (1963) Industrial Applications of Bentonite. Clays and Clay Minerals, 10, 272-283.

http://www.clays.org/journal/archive/volume\%2010/10-1-272.pdf https://doi.org/10.1346/CCMN.1961.0100122

[3] Rodrigues, F.A., Monteiro, P.J.M. and Sposito, G. (1999) The Alkali-Silica Reaction: The Surface Charge Density of Silica and Its Effect on Expansive Pressure. Cementand Concrete Research, 29, 527-530. https://doi.org/10.1016/S0008-8846(98)00220-8

[4] Yong, S. and Hubble, M.A. (2008) Polyelectrolyte Titrations of Synthetic Mineral Microparticle Suspensions to Evaluate Charge Characteristics. Colloids and Surfaces A: Physicochemical Engineering Aspects, 331, 175-182. https://doi.org/10.1016/j.colsurfa.2008.08.003

[5] Amadio, T.M., Hotza, D., Rodrigues, J.B., Blosi, M., Costa, A.L. and Dondi, M. (2017) Bentonite Functionalized by Impregnation with $\mathrm{TiO}_{2}, \mathrm{Ag}$, Pd and Au Nanoparticles. Applied Clay Science, 146, 1-6. https://doi.org/10.1016/j.clay.2017.05.028

[6] Park, J.-H., Shin, H.-J., Kim, M.-H., Kim, J.-S., Kang, N., Lee, J.-Y., Kim, K.-T., Lee, J.I. and Kim, D.-D. (2016) Application of Montmorillonite in Bentonite as Pharmaceutical Excipient in Drug Delivery Systems. Journal of Pharmaceutical Investigation, 46, 363-375. https://doi.org/10.1007/s40005-016-0258-8

[7] Razakamanantsoa, A.R., Barast, G. and Djeran-Maigre, I. (2012) Hydraulic Performance of Activated Calcium Bentonite Treated by Polyionic Charged Polymer. Applied Clay Science, 59-60, 103-114. https://doi.org/10.1016/j.clay.2012.01.022

[8] Magzoub, M.I., Nasser, M.S., Hussein, I.A., Benamor, A., Onaizi, S.A., Sutan, A.S. and Mahmoud, M.A. (2017) Effect of Sodium Carbonate Addition, Heat and Agitation on Swelling and Rheological Behavior of Ca-Bentonite Colloidal Dispersions. Applied Clay Science, 147, 176-183. https://doi.org/10.1016/j.clay.2017.07.032

[9] Wilkinson, N., Metaxas, A., Brichetto, E., Wickramaratne, S., Reineke, T.M. and Dutcher, C.S. (2017) Ionic Strength Dependence of Aggregate Size and Morphology On Polymer-Clay Flocculation. Colloids and Surfaces A: Physicochemical Engineering Aspects, 529, 1037-1046. https://doi.org/10.1016/j.colsurfa.2017.06.085

[10] Wilkinson, N., Metaxas, A., Quinney, C., Wickramaratne, S., Reineke, T.M. and Dutcher, C.S. (2018) pH Dependence of Bentonite Aggregate Size and Morphology on Polymer-Clay Flocculation. Colloids and Surfaces A: Physicochemical Engineering Aspects, 537, 281-286. https://doi.org/10.1016/j.colsurfa.2017.10.007

[11] Karagüzel, C., Çentinel, T., Boylu, F., Çunku, K. and Çelic, M.S. (2010) Activation of ( $\mathrm{Na}, \mathrm{Ca})$-Bentonites with Soda and $\mathrm{MgO}$ and Their Utilization as Drilling Mud. Applied Clay Science, 48, 398-404. https://doi.org/10.1016/j.clay.2010.01.013

[12] Villabona-Estupinán, S., de Almeida Rodrigues, J. and Nascimento, R.S.V. (2017) Understanding the Clay-PEG (and Hydrophobic Derivatives) Interactions and Their Effect on Clay Hydration and Dispersion: A Comparative Study. Applied Clay 
Science, 143, 89-100. https://doi.org/10.1016/j.clay.2017.03.021

[13] Song, K., Wu, Q., Li, M.-C., Wojtanowicz, A.K., Dong, L., Zhang, X., Ren, S. and Lei, T. (2016) Performance of Low Solid Bentonite Drilling Fluids Modified by Cellulose Nanoparticles. Journal of Natural Gas Scienceand Engineering, 34, 1403-1411. https://doi.org/10.1016/j.jngse.2016.08.036

[14] Yang, L., Jiang, G., Shi, Y., Lin, X. and Yang, X. (2017) Application of Ionic Liquid to a High-Performance Calcium-Resistant Additive for Filtration Control of Bentonite/Water-Based Drilling Fluids. Journalof Materials Science, 52, 6362-6375. https://doi.org/10.1007/s10853-017-0870-7

[15] Afolabi, R.O., Orodu, O.D. and Efeovbokhan, V.E. (2017) Properties and Application of Nigerian Bentonite Clay Deposits for Drilling Mud Formulation: Recent Advances and Future Prospect. Applied Clay Science, 143, 39-49.

https://doi.org/10.1016/j.clay.2017.03.009

[16] Xie, G., Luo, P., Deng, M., Su, J., Wang, Z., Gong, R., Xie, J., Deng, S. and Duan, Q. (2017) Intercalation Behavior of Branched Polyethylenemine into Sodium Bentonite and Its Effect on Rheological Properties. Applied Clay Science, 141, 95-103.

https://doi.org/10.1016/j.clay.2017.02.018

[17] Sasmal, D., Singh, R.P. and Tripathy, T. (2015) Synthesis and Flocculation Characteristics of a Novel Biodegradable Flocculating Agent Amylopectin-g-poly(acrylamide-co- $N$-methylacrylamide). Colloids and Surfaces A: Physicochemical Engineering Aspects, 482, 575-584. https://doi.org/10.1016/j.colsurfa.2015.07.017

[18] Kadooka, H., Kiso, Y., Goto, S., Tanaka, T., Jami, M.S. and Iwata, M. (2017) Flocculation Behavior of Colloidal Suspension by Use of Inorganic and Polymer Flocculants in Powder Form. Journal of Water Process Engineering, 18, 169-175. https://doi.org/10.1016/j.jwpe.2017.05.011

[19] Addai-Mensah, J., Yeap, K.Y. and MaFarlane, A.J. (2007) The Influential Role of Pulp Chemistry, Flocculant Structure Type and Shear Rate on Dewaterability of Kaolinite and Smectite Clay Dispersions under Coquette Taylor Flow Conditions. Powder Technology, 179, 79-83. https://doi.org/10.1016/j.powtec.2006.11.007

[20] O'Shea, J.-P. and Tallón, C. (2011) The Effect of Salt Concentration and pH om the Solid-Liquid Separation of Silica Suspensions with a Temperature-Responsive Flocculant. Separation and Purification Technology, 82, 167-176. https://doi.org/10.1016/j.seppur.2011.09.007

[21] Franks, G.V., O'Shea, J.-P. and Forbes, E. (2014) Controlling Thickener Underflow Rheology using a Temperature Responsive Flocculant. AIChE Journal, 60, 2940-2948. http://onlinelibrary.wiley.com/doi/10.1002/aic.14469/full https://doi.org/10.1002/aic.14469

[22] Schwarz, S., Ponce-Vargas, S.M., Licwa-Claverie, A. and Steinbach, C. (2012) Chitosan and Mixtures with Aqueous Biocompatible Temperature Sensitive Polymer as Flocculants. Colloids and Surfaces A: Physicochemical Engineering Aspects, 413, 7-12. https://doi.org/10.1016/j.colsurfa.2012.03.048

[23] Indulekha, S., Arunkumar, P., Bahadur, D. and Srivastava, R. (2017) Dual Responsive Magnetic Composite Nanogels for Thermos-Chemotherapy. Colloids and Surfaces B. Biointerfaces, 155, 304-313. https://doi.org/10.1016/j.colsurfb.2017.04.035

[24] Hashimoto, T., Takahashi, A., Urushisaki, M. and Sakaguchi, T. (2010) Synthesis of Poly(vinyl ether) Polyols with Pendant Oxyethylene Chains and Properties of Hydrophilic, Thermos-Responsive Polyurethanes Prepared Therefrom. Polymer Chemistry, 48, 1641-1648. https://doi.org/10.1002/pola.23930 
http://onlinelibrary.wiley.com/doi/10.1002/pola.23930/abstract

[25] Winnik, F.M., Ringsdorf, H. and Venzmer, J. (1990) Methanol-Water as a Co-Nonsolvent System for Poly( $N$-isopropylacrylamide). Macromolecules, 23, 2415-1416. https://doi.org/10.1021/ma00210a048

[26] Cheng, H., Shen, L. and Wu, C. (2006) LLS and FTIR Studies on the Hysteresis in Association and Dissociation of Poly( $N$-isopropylacrylamide) Chains in Water. Macromolecules, 39, 2325-2329. https://doi.org/10.1021/ma052561m

[27] Etika, K.C., Liu, L., Cox, M.A. and Grunlan, J.C. (2016) Clay-Mediated Carbon Nanotube Dispersion in Poly( $N$-isopropylacrylamide). Colloids and Surfaces A: Physicochemical Engineering Aspects, 489, 19-26. https://doi.org/10.1016/j.colsurfa.2015.09.024

[28] Zhang, F., Wu, W., Zhang, X., Meng, X., Tong, G. and Deng, Y. (2016) Temperature-Sensitive Poly-NIPAm Modified Cellulose Nanofibril Cryogel Microspheres for Controlled Drug Release. Cellulose, 23, 415-425.

https://link.springer.com/article/10.1007/s10570-015-0799-4 https://doi.org/10.1007/s10570-015-0799-4

[29] Liu, L., Zeng, J., Zhao, X., Tian, K. and Liu, P. (2017) Independent Temperature and pH Dual-Responsive PMAA/PNIPAM Microgels as Drug System: Effect of Swelling Behavior of the Core and Shell Materials in Fabrication Process. Colloids and Surfaces A: Physicochemical Engineering Aspects, 526, 48-55. https://doi.org/10.1016/j.colsurfa.2016.11.007

[30] Depa, K., Strachota, A., Šlouf, M., Brus, J. and Cimrová, V. (2017) Synthesis of Conductive Doubly Filled Poly( $N$-isopropylacrylamide)-Polyaniline-SiO ${ }_{2}$ Hydrogels. Sensors and Actuators. B Chemical, 244, 616-634. https://doi.org/10.1016/j.snb.2016.12.121

[31] O’Shea, J.-P., Qiao, G.G. and Franks, G.V. (2010) Solid-Liquid Separations with a Temperature-Responsive Polymeric Flocculant: Effect of Temperature and Molecular Weight on Polymer Adsorption and Deposition. Journal of Colloid and Interface Science, 348, 9-23. https://doi.org/10.1016/j.jcis.2010.04.063

[32] Ng, W.S., Connal, L.A., Forbes, E., Mohanarangam, K. and Franks, G.V. (2017) In Situ Investigation of Aggregate Sizes Formed using Thermos-Responsive Polymers: Effect of Temperature and Shear. Journal of Colloid and Interface Science, 494, 139-152. https://doi.org/10.1016/j.jcis.2017.01.067

[33] Lemanowicz, M., Gierczycki, A., Kuźnik, W., Sancewicz, R. and Imiela, P. (2014) Determination of Lower Critical Solution Temperature of Thermosensitive Flocculants. Minerals Engineering, 69, 170-176. https://doi.org/10.1016/j.mineng.2014.07.022

[34] Sawada, S., Kimura, R. and Murakami, K. (2016) Preparation of Thermo-Responsive Separation Membrane and Evaluation of Its Separation Properties. Journal of Chemical Engineering of Japan, 42, 107-112. (In Japanese)

[35] Murakami, K., Watanabe, A., Kato, T. and Sugawara, K. (2013) Transition Temperature Control of Adsorption-Desorption Property of PNIPAM/Mesoporous Silica Composite by Addition of Crosslinking Agent. Colloids and Surfaces A: Physicochemical Engineering Aspects, 419, 223-227. https://doi.org/10.1016/j.colsurfa.2012.11.074

[36] Fujishige, S. (1987) Intrinsic Viscosity-Molecular Weight Relationships for Poly ( $N$-isopropylacrylamide) Solutions. Polymer Journal, 19, 297-300.

https://www.nature.com/articles/pj198731

https://doi.org/10.1295/polymj.19.297 
[37] Orucogle, E. and Schroeder, P.A. (2016) Investigating the Expanding Behavior and Thermal Stability of HDPy Modified Organo-Bentonite by X-Ray Diffraction Technique. Applied Clay Science, 132-133, 90-95. https://doi.org/10.1016/j.clay.2016.05.021

[38] Nakamaura, A., Sugawara, K., Nakajima, S. and Murakami, K. (2017) Adsorption of Cs Ions using a Temperature-Responsive Polymer/Magnetite/Zeolite Composite Adsorption and Separation of the Adsorbent from Water using High-Gradient Magnetic Separation. Colloids and Surfaces A: Physicochemical Engineering Aspects, 527, 63-69. https://doi.org/10.1016/j.colsurfa.2017.05.032

[39] Liu, Q., Zhang, P., Qing, A., Lan, Y., Shi, J. and Lu, M. (2006) Synthesis of Rapid Responsive Gels Comprising Hydrophilic Backbone and Poly $(N$-isopropylacrylamide) Graft Chains by RAFT Polymerization and End-Linking Process. Polymer, 47, 6963-6969. https://doi.org/10.1016/j.polymer.2006.08.009

[40] Kurečič, M., Sfiligj-Smole, M. and Stana-Kleinschek, K. (2012) UV Polymerization of Poly( $N$-isopropylacrylamide) Hydrogel. Materials and Technology, 46, 87-91. https://www.dlib.si/details/URN:NBN:SI:DOC-EM3QGTGJ http://mit.imt.si/Revija/izvodi/mit121/kurecic.pdf

[41] Fan, R.-D., Du, S.-Y., Reddy, K.R. and Yang, Y.-L. (2017) Impacts of Presence of Lead Contamination on Settling Behavior and Microstructure of Clayey Soil-Calcium Bentonite Blends. Applied Clay Science, 142, 109-119.

https://doi.org/10.1016/j.clay.2016.10.042

[42] Gupta, B., Rakesh, A., Melvin, A.A., Pandey, A.C. and Prakash, R. (2014) In-Situ Synthesis of Polyaniline Coated Montmorillonite (Mt) Clay using $\mathrm{Fe}^{3+}$ Intercalated Mt as Oxidizing Agent. Applied Clay Science, 95, 50-54. https://doi.org/10.1016/j.clay.2014.02.009

[43] Clegg, F., Breen, C. and Khairuddin (2014) Synergistic and Competitive Aspects of the Adsorption of Poly(ethylene glycol) and Poly(vinyl alcohol) onto Na-Bentonite. The Journal of Physical Chemistry B, 118, 13268-13278. https://doi.org/10.1021/jp507772t

[44] Hou, X.-J., Li, H., Liu, Q., Cheng, H., He, P. and Li, S. (2015) Theoretical Study for the Interlamellar Aminoalcohol Functionalization of Kaolinite. Applied Surface Science, 347, 439-447. https://doi.org/10.1016/j.apsusc.2015.04.117

[45] Li, J., Song, X., Pan, J., Zhong, L., Jiao, S. and Ma, Q. (2013) Adsorption and Flocculation of Bentonite by Chitosan with Varying Degree of Deacetylation and Molecular Weight. International Journal of Biological Macromolecules, 62, 4-12. https://doi.org/10.1016/j.ijbiomac.2013.08.009 